\title{
ANTIMICROBIAL ACTIVITY OF THE ESSENTIAL OIL OF THYMUS CAPITATUS AGAINST HELICOBACTER PYLORI
}

\author{
MERYEM GÜVENIR ${ }^{1 *}$, DUYGU HANOĞLU ${ }^{2}$, AZMİ HANOĐLU ${ }^{2}$, KAYA SÜER ${ }^{3}$, \\ HÜSNÜ CAN BAŞER ${ }^{4}$, DUDU ÖZKUM YAVUZ ${ }^{2}$ and TAMER ŞALIDAG ${ }^{5,6}$
}

'Department of Microbiology, Vocational School of Health Services, Near East University, Nicosia, Cyprus

${ }^{2}$ Department of Pharmaceutical Botany, Faculty of Pharmacy, Near East University, Nicosia, Cyprus

${ }^{3}$ Department of Infectious Diseases and Clinical Microbiology, Faculty of Medicine, Near East University, Nicosia, Cyprus

${ }^{4}$ Department of Pharmacognosy, Faculty of Pharmacy, Near East University, Nicosia, Cyprus

${ }^{5}$ Reserach Center of Experimental Health Sciences, Near East University, Nicosia, Cyprus

${ }^{6}$ Department of Medical Microbiology, Faculty of Medicine, Celal Bayar University, Manisa, Turkey

\begin{abstract}
Helicobacter pylori (H.pylori) is an infective agent and the main resourceful factor of chronic, active type B gastritis, peptic and duodenal ulcer, gastric carcinoma and mucosa-associated lymphoid tumors. Nowadays, pharmcological treatment of $H$. pylori infections attracts attention besides antibiotic treatment. The aim of this study is to analyse the chemical composition of the essential oils of Thymus capitatus and the antimicrobial activity against $H$. pylori. Aerial parts of wild-growing plant materials were collected during the flowering stage from three different locations. Essential oil composition analyses were performed simultaneously by GC-FID and GC-MS systems. The antimicrobial activity of the essential oil was tested by broth dilution method. The thymol percentage was determined as more than half of the essential oil composition of Thymus capitatusYedidalga (51.9\%) and Thymus capitatus -Yıldirtm (57.1\%); however, the composition of thymol was $47.2 \%$ followed by $15.1 \%$ (p-cymene), $10.0 \%$ ( $\gamma$-terpinene) and $5.7 \%$ (carvacrol) for Thymus capitatus-Boğaz/Girne. The essential oil from Thymus capitatus- Boğaz/Girne showed the lowest MIC and MBC values and the strongest bactericidal activity against $H$. pylori compared to the other tested essential oils. Bactericidal efficacy of essential oil of Thymus capitatus on $H$. pylori could have been affected due to the varied rates of major compounds. Thymus capitatus essential oil could be an alternative way for the treatment of $H$. pylori infections.
\end{abstract}

Keywords: Helicobacter pylori, Thymus capitatus, in vitro, essential oil

Helicobacter pylori (H. pylori) is a Gram-negative spiral bacterium identified in 1982 that is accepted as a critical causal agent in gastroduodenal diseases including chronic gastritis, peptic ulceration, gastric adenocarcinoma and mucosaassociated lymphoid tissue lymphoma (MALT) (13). The first data on the prevalence and molecular characteristics of $H$. pylori was produced by Krashias et al. in Cyprus. Krashias et al. found that the prevalence of the $H$. pylori was $39.8 \%$ (41/103) (3). The treatment of $H$. pylori infection includes standard triple therapy with proton pump inhibitors. In addition to these therapies, studies have indicated that adjuvant therapy such as probiotics, bovine lactoferrin and curcumin can lower the side effects of triple therapy and can increase the treatment effectiveness (4).

The genus Thymus, which belongs to the Lamiaceae family, is rich in essential oils (EO). thymol, carvacrol, $\gamma$-terpinene and $p$-cymene are the principal components of Thymus essential oils with different ratios and these components are responsible for the pharmacological effects $(5,6)$. In general, the ranges among the percentages of the major compounds in the EO composition are represented as chemotypes in nature. If the quantity of a com-

* Corresponding author: e-mail: meryemguvenir@hotmail.com 
pound is more than half of the EO, this chemotype is called "pure"; however, if there are multiple dominant compounds, this chemotype is called "mixed". In the literature, various chemotypes of the Thymus genus have been reported around the World (7-12). This genus is represented by two species in Cyprus: Thymus capitatus (L.) Hoffmanns. \& Link and Thymus integer Griseb Ethnobotanical surveys in Cyprus have shown that T. capitatus is one of the most widely known and used aromatic plants for medicinal purposes for the preservation of health, as well as for the treatment of various diseases $(1,13)$. The aerial parts of this species are used in Cyprus to treat some respiratory tract infections, gastrointestinal and cardiovascular system disorders in the form of tea or by chewing (14-17). Additionally, for the treatment of mouth ulcers and oral cancers, the young leaves of $T$. capitatus are used by chewing in Northern Cyprus folk medicine (18). The antimicrobial activity of the EO $(19,20)$ and the extracts $(21$, 22) of this genus against $H$. pylori has been previously reported.

To the best of the author's knowledge, no work has been conducted on the antimicrobial activity of the essential oil of T. capitatus against $H$. pylori. In the present study, it is aimed to analyze the chemical composition of the essential oils of $T$. capitatus collected from three different regions and the antimicrobial activity of these oils against $H$. pylori.

\section{EXPERIMENTAL}

\section{Plant materials}

The aerial parts of the plant materials growing wild in Northern Cyprus were collected during the flowering stages. Samples were gathered from three different locations in Northern Cyprus, designated as the western (Yedidalga) (Tc1), eastern (Y1ldırım) (Tc2), and northern (Boğaz-Girne) (Tc3) regions. Voucher specimens were kept at the Herbarium of Near East University (NEUN). The Herbarium numbers of Tc1, Tc2 and Tc3 are NEUN 6882, 6881 and 6883 , respectively.

\section{Isolation of essential oil}

One hundred grams of air-dried aerial parts of the plant material was hydrodistilled with $1 \mathrm{~L}$ of water for $3 \mathrm{~h}$ in a Clevenger-type apparatus. The EO were stored at $4^{\circ} \mathrm{C}$ until analysis. The yields were calculated as w/w by using a pycnometer. Stock $T$. capitatus EO was prepared in dimethylsulfoxide (DMSO, Sigma-Aldrich) and dissolved in $10 \%$ DMSO. The concentration rate of EO was $90 \%$.

\section{GC/MS analysis}

The GC-MS analysis was conducted with an Agilent 5975 GC-MSD system. Innowax FSC column $(60 \mathrm{~m} \times 0.25 \mathrm{~mm}, 0.25 \mathrm{~mm}$ film thickness $)$ was used with helium as the carrier gas $(0.8 \mathrm{~mL} / \mathrm{min})$. The GC oven temperature was kept at $60^{\circ} \mathrm{C}$ for 10 min and the programmed to $220^{\circ} \mathrm{C}$ at a rate of $4^{\circ} \mathrm{C} / \mathrm{min}$, kept constant at $220^{\circ} \mathrm{C}$ for $10 \mathrm{~min}$ and then programmed to $240^{\circ} \mathrm{C}$ at a rate of $1^{\circ} \mathrm{C} / \mathrm{min}$. The split ratio was adjusted at $40: 1$. The injector temperature was set at $250^{\circ} \mathrm{C}$. Mass spectra were recorded at 70 $\mathrm{eV}$. Mass range was from m/z 35 to 450 .

\section{GC analysis}

The GC analysis was conducted using an Agilent $6890 \mathrm{~N}$ GC system. The FID detector temperature was $300^{\circ} \mathrm{C}$. To obtain the same elution order with GC-MS, simultaneous auto-injection was performed on a duplicate of the same column applying the same operational conditions. Relative percentage amounts of the separated compounds were calculated from FID chromatograms.

\section{Identification of components}

Identification of the EO components was conducted by comparison of their relative retention times with those of authentic samples or by comparison of their relative retention index (RRI) to a series of $n$-alkanes. Computer matching against commercial (Wiley GC/MS Library, Adams Library, MassFinder 3 Library) $(23,24)$ and in-house "Başer Library of Essential Oil Constituents" built up by genuine compounds and components of known oils, as well as MS literature data $(25,26)$ was used for the identification.

\section{H. pylori strain}

H. pylori ATCC 43504 was obtained from the American Type Culture Collection (Rockville, MD, USA) and then used in this study.

\section{Preparation of stock clarithromycin solution}

Clarithromycin solution was prepared by dissolving $25 \mathrm{mg}$ clarithromycin in $25 \mathrm{~mL}$ methanol. 9 $\mathrm{mL}$ of phosphate-buffered saline was added into 1 $\mathrm{mL}$ of clarithromycin solution and the stock solution was obtained as $100 \mu \mathrm{g} / \mathrm{mL}(\mathrm{w} / \mathrm{v})$. The stock solution was sterilized with $0.22 \mu \mathrm{m}$ sterile syringe filter and 2-fold serial dilutions were made in phosphatebuffered saline.

\section{Antimicrobial activity of EO}

The broth microdilution method was performed as recommended by Lesjak et al. (27) and 
Table 1. The essential oil compositions of the three localities of T. capitatus from Northern Cyprus.

\begin{tabular}{|c|c|c|c|c|}
\hline RRI & Compound & $1 \%$ & $2 \%$ & $3 \%$ \\
\hline 1032 & $\alpha$-Pinene & 1.0 & 0.8 & 1.1 \\
\hline 1035 & $\alpha$-Thujene & 0.5 & 0.6 & 0.9 \\
\hline 1076 & Camphene & 0.7 & 0.5 & 0.9 \\
\hline 1118 & $\beta$-Pinene & 0.2 & 0.2 & 0.3 \\
\hline 1159 & $\delta$-Car-3-en & - & 0.1 & 0.1 \\
\hline 1174 & Myrcene & 1.7 & 1.8 & 2.2 \\
\hline 1176 & $\alpha$-Phellandrene & 0.2 & 0.3 & 0.4 \\
\hline 1188 & $\alpha$-Terpinene & 1.5 & 2.0 & 2.3 \\
\hline 1203 & Limonene & 1.3 & 0.9 & 1.0 \\
\hline 1218 & -Phellandrene & 0.5 & 0.5 & 0.6 \\
\hline 1255 & $\gamma$-Terpinene & 4.9 & 6.9 & 10.0 \\
\hline 1280 & $p$-Cymene & 13.6 & 12.3 & 15.1 \\
\hline 1290 & Terpinolene & 0.5 & 0.6 & 0.5 \\
\hline 1452 & Oct-1-en-3-ol & 0.9 & 0.7 & 1.0 \\
\hline 1474 & trans-Sabinene hydrate & 0.1 & 0.1 & 0.2 \\
\hline 1553 & Linalool & 0.6 & 0.2 & 0.5 \\
\hline 1604 & Thymol methyl ether & 0.2 & 0.1 & 0.2 \\
\hline 1611 & Terpinen-4-ol & 0.6 & 0.4 & 0.4 \\
\hline 1612 & $\beta$-Caryophyllene & 2.0 & 2.1 & 2.2 \\
\hline 1694 & Neral & 0.4 & 0.3 & 0.2 \\
\hline 1706 & $\alpha$-Terpineol & 0.5 & 0.3 & 0.3 \\
\hline 1708 & Ledene & $\operatorname{tr}$ & 0.7 & - \\
\hline 1719 & Borneol & 3.7 & 1.1 & 3.0 \\
\hline 1740 & Geranial & 0.5 & 0.4 & 0.4 \\
\hline 1741 & $\beta$-Bisabolene & 0.1 & - & 0.2 \\
\hline 1751 & Carvone & 0.1 & $\operatorname{tr}$ & $\operatorname{tr}$ \\
\hline 1784 & $(E)$ - $\alpha$-Bisabolene & 0.1 & - & 0.2 \\
\hline 1808 & Nerol & 0.2 & 0.2 & 0.3 \\
\hline 1857 & Geraniol & 0.1 & 0.2 & 0.1 \\
\hline 1864 & $p$-Cymen-8-ol & 0.2 & & 0.2 \\
\hline 2008 & Caryophyllene oxide & 0.6 & 0.4 & 0.5 \\
\hline 2144 & Spathulenol & 0.3 & 0.2 & 0.2 \\
\hline 2181 & Isothymol & 0.3 & 0.2 & 0.3 \\
\hline 2186 & Eugenol & 0.3 & 0.3 & 0.3 \\
\hline 2198 & Thymol & 51.9 & 57.1 & 47.2 \\
\hline 2221 & Isocarvacrol & 1.2 & 1.0 & 1.0 \\
\hline \multirow[t]{2}{*}{2239} & Carvacrol & 8.5 & 6.5 & 5.7 \\
\hline & Total & 100.0 & 100.0 & 100.0 \\
\hline
\end{tabular}

1: Thymus capitatus - Yedidalga, 2: Thymus capitatus - Yildirim, 3 Thymus capitatus - Bogaz/Girne, RRI Relative retention indices calculated against n-alkanes, \% calculated from FID data, tr Trace $(<0.1 \%)$ 
clarithromycin was used as the positive control. The bacterial suspensions were adjusted to $2 \times 10^{8}$ $\mathrm{CFU} / \mathrm{mL}^{-1}$ standard turbidity. The prepared $\mathrm{EO}$ were placed in wells and inoculated brain heart infusion broth was added. The microplates were incubated for $48 \mathrm{~h}$ with an aeropack system. After the incubation period, $100 \mu \mathrm{L}$ aliquots of the medium were plated on $H$. pylori agar plates. Colonies were counted after incubation for 5 days. DMSO was used to enhance oil solubility, therefore it was accepted that DMSO had no bacterial effect against $H$. pylori and was tested as a negative control.

The minimal inhibitory concentration (MIC) was determined as the lowest concentration of the sample that prevented visible growth and the minimum bactericidal concentration (MBC) was determined by the lowest concentration resigned negative subcultures or only one colony.

\section{RESULTS}

\section{The chemical composition of the EO from three} different locations

The EO of Tc1, Tc2 and Tc3 were analyzed by GC-FID and GC-MS systems simultaneously. The composition of EO obtained from three locations was identified in percentages (Table 1). The number of compounds identified from Tc1 (Yedidalga), Tc2 (Yıldırım) and Tc3 (Boğaz-Girne) was 36, 34 and 36 , respectively. The thymol percentage was determined as more than half of the EO composition of Tc1 (Yedidalga (51.9\%) and Tc2 (Y1ldırım)) (57.1\%); however, the composition of thymol was $47.2 \%$ followed by $15.1 \%$ ( $p$-cymene), $10.0 \%(\gamma$ terpinene) and $5.7 \%$ (carvacrol) for Tc3 (BoðazGirne).

\section{Antimicrobial activity against $\boldsymbol{H}$. pylori}

Tc1 (Yedidalga), Tc2 (Y1ldirım) and Tc3 (Boğaz-Girne) MIC values were $<0.5 \mu \mathrm{g} / \mathrm{mL},<0.5$ $\mu \mathrm{g} / \mathrm{mL}$ and $<0.25 \mu \mathrm{g} / \mathrm{mL}$, respectively. The EO from Tc3 (Boğaz-Girne) showed the lowest MIC and MBC values and the strongest bactericidal activity against $H$. pylori compared to the other tested EO. The MIC and MBC values are given in Table 2.

\section{DISCUSSION AND CONCLUSION}

At the present time, there are problems with treatments against $H$. pylori infection including multidrug resistance, high expenses, drug interventions, poor satisfaction, side effects and their brunt on the normal intestinal flora (28). In the last decade, interest in EOs has increased on their bactericidal, virucidal, fungicidal and antiparasitic effects (29) due to the fact that interest in studying the antimicrobial activities of the EO has been increasing. Additionally, the traditional uses of medicinal plants could lead to improvement in the treatment of infections such as gastroduodenal diseases.

According to the results of chemical composition and antimicrobial activity against $H$. pylori of the essential oils, Tc3 (Boğaz-Girne was determined the most active in all three tested EOs. Furthermore, the rate of thymol/carvacrol decreased, while the rate of $\gamma$-terpinene/ $p$-cymene increased for Tc3 (Boğaz-Girne) in comparison with Tc1 (Yedidalga) and Tc2 (Yıldırım)). The results of the chemical contents of the essential oils of T. capitatus shows that Tc1 (Yedidalga and Tc2 (Yıldırım)) is found as pure thymol chemotypes due to the rate of thymol, while Tc3 (Boğaz-Girne) is found as a mixed chemotype. In the literature, it is found that carvacrol chemotypes $(8,11,13)$ of T. capitatus are common while thymol chemotypes are rare $(14,30,31)$. Lesjak et al. reported that Satureja hortensis, Origanum vulgare subsp. vulgare and $O$. vulgare subsp. hirtum EOs demonstrate the highest activity ( $\mathrm{MIC}=2 \mu \mathrm{g} / \mathrm{mL}$ ) against $H$. pylori (27) .Eftekhar et al. reported that the antimicrobial activity of the EO of $T$. caramanicus against $H$. pylori was higher than the clarithromycin (19) and these results were supported in this study's

Table 2. Minimum Inhibitory Concentrations (MICs) and Minimum bactericidal concentration (MBC) of tested essential oils against $H$. pylori.

\begin{tabular}{|c|c|c|c|}
\hline \multirow{2}{*}{ Essential Oil } & Location & MIC $(\mu \mathrm{g} / \mathrm{mL})$ & $\mathrm{MBC}(\mu \mathrm{g} / \mathrm{mL})$ \\
\hline \multirow{3}{*}{ Thymus capitatus } & $\mathrm{Tc} 1$ & $<0.5$ & 1.00 \\
\cline { 2 - 4 } & $\mathrm{Tc} 3$ & $<0.25$ & 0.50 \\
\cline { 2 - 4 } & $\mathrm{Tc} 2$ & $<0.5$ & 1.00 \\
\hline Positive control & Claritromycin & $<1$ & 1.00 \\
\hline Negative control & DMSO & -- & -- \\
\hline
\end{tabular}


results. In addition, the antimicrobial effect against H.pylori of the EO of Thymus sp. was found to be more effective than pure compounds such as carvacrol and thymol (19). We had limited studies with Thymus spp anti-H.pylori activity. Dandlen SA. et. al studied with different species of the Thymus spp. (T. caespititus) EO from Planalto Central and its main component, carvacrol is an effective inhibitor of $H$. pylori 26695 intracellular growth (32). In the present study, the highest thymol value was found in Tc2 (Yıldırım) (57.1\%); however, Tc3 (BoğazGirne was found as the most active against $H$. pylori. Therefore, it is possible to mention that the rates of the compounds in EO have shown a synergistic effect against H.pylori. However, we need further study to test pure components of thymol and carvacrol. In addition, according to study results, the use of carvacrol rich EO or its main components seems to have the potential to be used in combination with treatments potentiating a total eradication $(32,33)$.

According to the results of the present study, it is suggested that the $T$. capitatus EO could be an alternative for the treatment of $H$. pylori infections. Therefore, further investigations are needed in order to determine the in vivo antimicrobial activity against $H$. pylori of the $\mathrm{EO}$ obtained from $T$. capitatus growing wild in Northern Cyprus. Also, the limitation of our studies was limited studies with Thymus spp. anti-H. pylori activity and further studies should be done with pure components of thymol and carvacrol.

\section{Acknowledgments and disclosure}

The authors wish to thank Prof. Dr. Betuil Demirci (Anadolu University, Faculty of Pharmacy, Pharmacognosy Department) for her valuable contribution to the analysis of the essential oil compositions.

\section{Conflict of interests}

The authors declare no conflict of interest.

\section{REFERENCES}

1. Marshall B., Warren J. R.: Lancet 323, 1311 (1984).

2. Ohno T., Kita M., Yamaoka Y., Immamura S., Yamamoto T., et al.: Helicobacter 8, 207 (2003).

3. Krashias G., Bashiardes S., Potamitou A., Potamitis G.S., Christodoulou C.: J. Infect. Dev. Ctries. 7, 642 (2013).
4. Asha M.K., Debraj D., Prashanth D., Edwin J.R., Srikanth H.S., et al.: J. Ethnopharmacol. 145, 581 (2013).

5. Holopainen M., Hiltunen R., von Schantz M.: Planta Med. 53, 284 (1987).

6. Rodríguez-Solana R., Daferera D.J., Mitsi C., Trigas P., Pollissiou M., et al.: Ind. Crops Prod. 62, 22 (2014).

7. Kirimer N., Baţer K.H.C., Tümen G.: Chem. Nat. Compd. 31, 37 (1995).

8. Cosentino S., Tuberoso C.I.G., Pisano B., Satta M., Maseia V., at al.: Lett. Appl. Microbiol. 29, 130 (1999).

9. Goren A.C., Bilsel G., Bilsel M., Demir H., Kocabat E.E.: Z. Naturforsch. 58, 687 (2003).

10. Bounatirou S., Smiti S., Miguel M.G., Faleiro M.N., rejeb M., et.al.: Food Chem. 105, 146 (2007).

11. Economou G., Panagopoulos G., Tarantilis P., Kalivas D., Kotoulas V., et al.: Ind. Crops Prod. 33, 236 (2011).

12. Meikle R.D.: Flora of Cyprus Volume 2, pp. 833-1969, Edinburgh, London, Melbourne: Kew: The Bentham-Moxon Trust, Royal Botanic Gardens; Clark Constable, 1985.

13. Džamić A.M., Nikolić B.J., Giweli A.A., MiticCulafic D.S., Sokovic M.D., et al. J. Appl. Microbiol. 119, 389 (2015).

14. Maissa B.J., Walid H.: Nat. Prod. Res. 29, 869 (2015).

15. Lardos A., Heinrich M.: J. Ethnopharmacol. 150, 202 (2013).

16. Lardos A.: J. Ethnopharmacol. 104, 387 (2006).

17. González-Tejero M.R., Casares-Porcel M., Sánchez-Rojas CP., Ramiro-Gutierrez JM., Molero-Mesa J., et al.: J. Ethnopharmacol, 116, 341 (2008).

18. Ozan, Ç.: An Investigation on the Medicinal Plants of Northern Cyprus. Near East University Institute of Health Sciences, Department of Pharmacognosy-Pharmaceutic Botanic, MSc. Thesis, Nicosia 2011.

19. Eftekhar F., Nariman F., Yousefzadi M., Hadiand J., Ebrahim S.N.: Nat. Prod. Commun. 4, 1139 (2009).

20. Hazzit M., Baaliouamer A., Veríssimo A.R., Faleiro M.L., Miguel M.G.: Food Chem. 116, 714 (2009).

21. Nariman F., Eftekhar F., Habibi Z., Falsafi T.: Helicobacter 9, 146 (2004).

22. Ghannadi A., Sajjadi S.E., Abedi D., Yousefi J., Darei-Ardekoni R.: Niger. J. Nat. Prod. Med. 8, 40 (2004). 
23. McLafferty F.W., Stauffer D.B.: The Wiley/ NBS Registry of Mass Spectral Data, J. Wiley and Sons, New York 1989.

24. Koenig W.A., Joulain D., Hochmuth D.H.: in Terpenoids and Related Constituents of Essential Oils. MassFinder3. Hochmuth D.H. (ed). Convenient and Rapid Analysis of GCMS, Hamburg, Germany 2004.

25. Joulain D., Koenig W.A.: The Atlas of Spectra Data of Sesquiterpene Hydrocarbons, EBVerlag, Hamburg 1998.

26. ESO 2000. The Complete Database of Essential Oils, Boelens Aroma Chemical Information Service, The Netherlands 1999.

27. Lesjak M., Simin N., Orcic D., Franciskovic M., Knezevic P.: Phytother. Res. 31, 476 (2016).
28. Esmaeili D., Mobarez A.M., Tohidpour A.: Open Microbiol. J. 6, 65 (2012).

29. Albayrak S., Aksoy A.: J. Food Process. Preserv. 37, 605 (2012).

30. Fleisher Z., Fleisher A.: J. Essent. Oil Res. 14, 105 (2012).

31. Mkaddem M.G., Romdhane M., Ibrahim H., Ennarjar M., Lebrihi A., et al.: J. Med. Food 13, 1500 (2010).

32. Dandlen S.A., Lima S.A., Mendes M.D. Miguel M.G., Faleiro M.L., et al.: Rev. Bras. Farmacogn. 21, 1021 (2011).

33. Bergonzelli G.E., Donnicola D., Porta N., Corthesy-Theulaz I.E.: Antimicrob. Agents Chemother. 47, 3240 (2003).

C 2020 by Polish Pharmaceutical Society. This is an open access article under the CC BY NC license (http://creativecommons.org/licenses/BY/4.0/). 